\title{
EAR BLAST INJURY IN MILITARY POPULATION: A 12 MONTHS FOLLOW-UP
}

\author{
Mezri S, Karouia J, Ben M'hamed R, Khemaies A \\ ENT department. Military hospital of Tunis. Tunisia
}

\begin{tabular}{l}
\hline Introduction \\
- Otological accidents resulting from mine explosions are polymorphous, mainly \\
affecting deployed military personnel. \\
- A delayed treatment, usually by lack of knowledge and / or association of injuries \\
considered to be more serious, can worsen the auditory prognosis. \\
Material and Methods \\
- We have included patients treated for ear blast injury secondary to terrorist attacks at \\
the ENT department of the Military Hospital of Tunis between 2011 and 2017 . \\
- All patients underwent a clinical evaluation and an audiometric exploration before \\
and after 12 months of the accident. \\
- Severity of hearing loss was be categorized using the American Speech Language- \\
Hearing Association (ASHA) threshold-based classification system. \\
- Results \\
-90 patients, $0: 100 \%$ \\
$\because$ Average age $=25$ years $[20$ to 42 years old] \\
- Circumstances of the accident: - Terrorist act (100\%)
\end{tabular}

cases $(17 \%)$

Open space 75 cases (83\%) / Closed space 15

$64 \%$ were less than 10 meters from the center

of the explosion and $30 \%$ were within 5 meters.

- Delay to ENT specialized exams : 12 hours to 3 months

- Initial otoscopic exam: Tympanic perforation ( in15 patients with 8 bilatera perforation)

- Audiometric exam: $65 \%$ of patient have perceptual hearing loss (Table 1) and more than $70 \%$ of patients have mild or moderately severe hearing loss (Table 2)

- Therapeutic protocol: - IV high-dose of corticosteroid (300 milligrams per day of $(\mathrm{HSHC}) \rightarrow$ All patients

Vasodilatators (for patients with tinnitus)

Preventive antibiotic (amoxicillin-clavulanic acid) : in the presence of hematoma or tympanic perforation.

- Hyperbaric oxygen therapy (HBOT) : patients with perceptual hearing loss or non-tolerated tinnitus: proposed for 53 cases $\rightarrow$ achieved by 33 patients $(63 \%)$.

-center ( $<10$ meters)

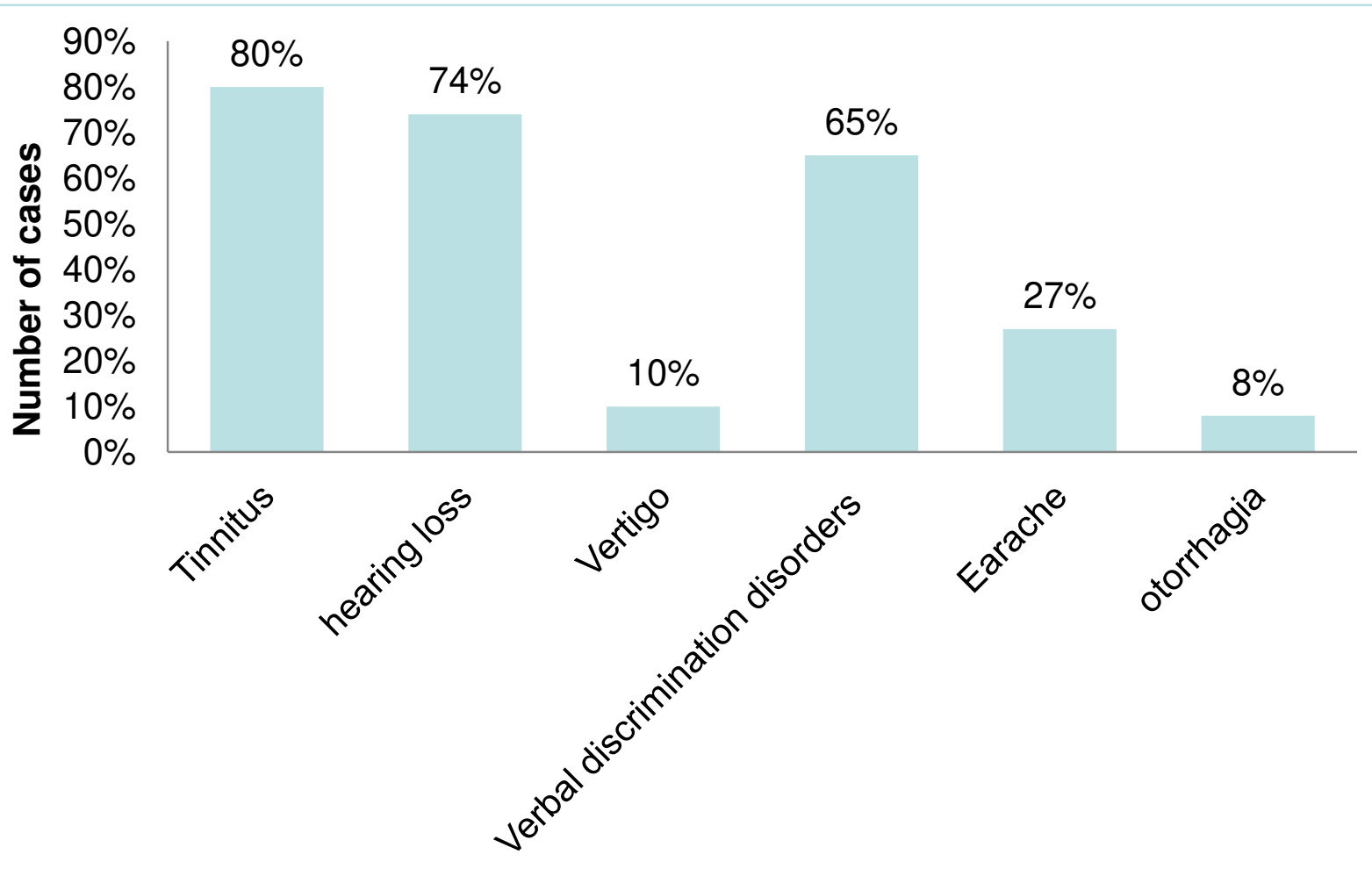

Initial Functional signs

\section{OUTCOME}

At 12 months of the accident

$20 \%(n=18)$ still have painful hyperacusis.

Tonal audimetry and the study of the PEA objectified an improvement of hearing in $26.6 \%$ of cases (average hearing gain of $20 \mathrm{~dB}$ )

- Worsening in $13 \%$ of cases by 15 to $20 \mathrm{~dB}$. (Table 2 )

of tinnitus

$37.5 \%$ of patients: disappearance or a significant decrease

Twelve patients were referred for psychiatric management for tinnitus-related sleep disorders and a professional reclassification was recommended for patients with severe or profound deafness

Table 1: Type of hearing loss

\begin{tabular}{|c|c|c|c|c|c|}
\hline \multirow{2}{*}{$\begin{array}{l}\begin{array}{l}\text { Type of } \\
\text { hearingloss }\end{array} \\
\text { Number of } \\
\text { cases (\%) }\end{array}$} & \multirow{2}{*}{$\begin{array}{c}\begin{array}{c}\text { perceptual } \\
\text { hearing loss }\end{array} \\
59(65)\end{array}$} & \multicolumn{2}{|c|}{$\begin{array}{c}\text { pure } \\
\text { transmission } \\
\text { deafness }\end{array}$} & $\begin{array}{l}\text { mixed hearing } \\
\text { loss }\end{array}$ & \multirow{3}{*}{$\begin{array}{c}\text { Normal } \\
6(7)\end{array}$} \\
\hline & & $7(8$ & & & \\
\hline & \multicolumn{3}{|c|}{ Table 2: Initial and final hearing loss degrees* } & \multirow[b]{2}{*}{$\begin{array}{l}\text { Severe } \\
{[71-90]}\end{array}$} & \\
\hline $\begin{array}{l}\text { hearing loss } \\
\text { degrees }^{*}(\mathrm{~dB})\end{array}$ & $\begin{array}{c}\text { Normal or } \\
\text { slight hearing } \\
\text { loss } \\
{[0-24]}\end{array}$ & $\begin{array}{c}\text { Mild } \\
{[25-40]}\end{array}$ & $\begin{array}{c}\text { Moderate or } \\
\text { Moderately } \\
\text { severe } \\
\text { [41-70] }\end{array}$ & & $\begin{array}{c}\text { Profound } \\
>91\end{array}$ \\
\hline $\begin{array}{l}\text { Initial } \\
\text { hearing loss } \\
n(\%)\end{array}$ & $10(11)$ & 29(32) & $36(40)$ & $15(17)$ & 0 \\
\hline $\begin{array}{l}\text { Hearing status at } \\
12 \text { months of } \\
\text { accident } n(\%)\end{array}$ & $13(15)$ & $36(40)$ & $27(30)$ & $12(13)$ & 2(2) \\
\hline
\end{tabular}

${ }^{*}$ Categorization according to thresholds defined by the ASHA; $\mathbf{n}$ : Number of cases

\section{TAKE HOME MESSAGES}

Outcome was better : Early treatment $(<48$ hours)

Medium initial deafness

HBOT was combined to steroid therapy

Individual protection (helmet,...),

Outcome was poor : Severe and / or bilateral pure sensorineural deafness Association with tinnitus

Late management

Proximity to the explosion

\section{Conclusion}

Ear blast injuries are polymorphic, affecting several components of the acoustic-vestibular system. However, the lack of parallelism between important functional complaints and poor clinical examination often leads to an under estimation of the diagnosis.

In any case, given the risk of secondary aggravation, regular monitoring and extended psychological support in these patients is largely justified.

\section{References}

-Sun $\mathrm{H}$, et al: Comparison of intratympanic dexamethasone therapy and hyperbaric oxygen therapy for the salvage treatment of refractory high-frequency sudden sensorineural hearing loss. AM J Otolaryngol. 2018; 39(5): 531-5.

-Remenschneider AK, et al: Otologic outcomes after blast injury: the Boston Marathon experience. Otol Neurotol 2014; 35(10): 1825-34. -Ballivet de Régloix S et al: Blast injury of the ear by massive explosion: a review of 41 cases. J R Army Med Corps. 2017; 163(5): 333-8.

\section{Author Names}

Sameh Mezri : ENT department. Military Hospital of Tunis. Tunisia (mezrisameh@gmail.com) - Jihène Karouia

- Rania Ben Mhamed

- Khemaies Akkari 